\title{
Costs and Benefits of Simplifying Diet and Exercise Rule Complexity
}

J acquelyn R. Nyenhuis (jrnyenhu@mtu.edu)

Edward T. Cokely (ecokely@mtu.edu)

Louisa D. Raisbeck (lraisbec@mtu.edu)

Department of Cognitive and Learning Sciences Michigan Technological University

\section{INTRODUCTION:}

Today, $98 \%$ of all diets fail (Jeffery 2000). One promising avenue for improving health outcomes focuses on improving diet and exercise adherence via reducing rule complexity.

Do people understand the benefits of simpler rules?

\section{HYPOTHESIS:}

We hypothesized that many people mistakenly believe that "complex is better" for diet and exercise programs.

\section{METHODS:}

We conducted an online survey $(\mathrm{N}=313)$ using Unipark survey software with paid participants from Amazon's Mechanical Turks. Demographics roughly matched key aspects of the US population.

\section{DEMOGRAPHICS:}

Gender: 131 Male; 182 female

Ages: Ranged from 18-67 (All US Residents)

BMI: 44\% had $\mathrm{BMI}<25 ; 56 \%$ had $\mathrm{BMI} \geq 25$; (7\% no answer)

High blood sugar or diabetes: $13 \%$ had been diagnosed

\section{EXPERIMENT 1: DIETS}

Presented two diets

Diets were equated on the following:

- Number of rules

- Number of words

- Diet efficacy*

*Data suggest that the simpler diet may be more effective (Camelon et al., 1998) Diet Complexity
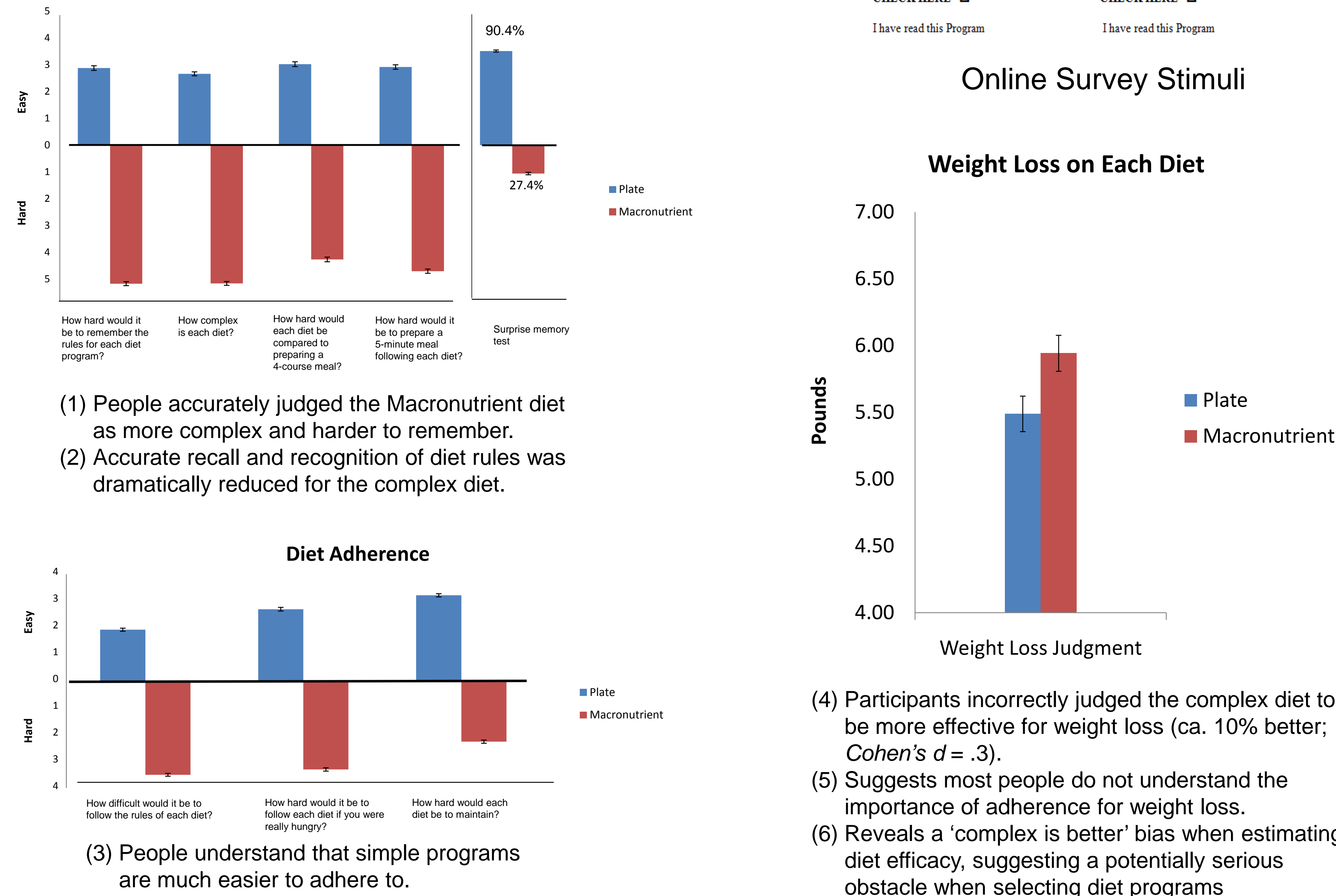
are much easier to adhere to
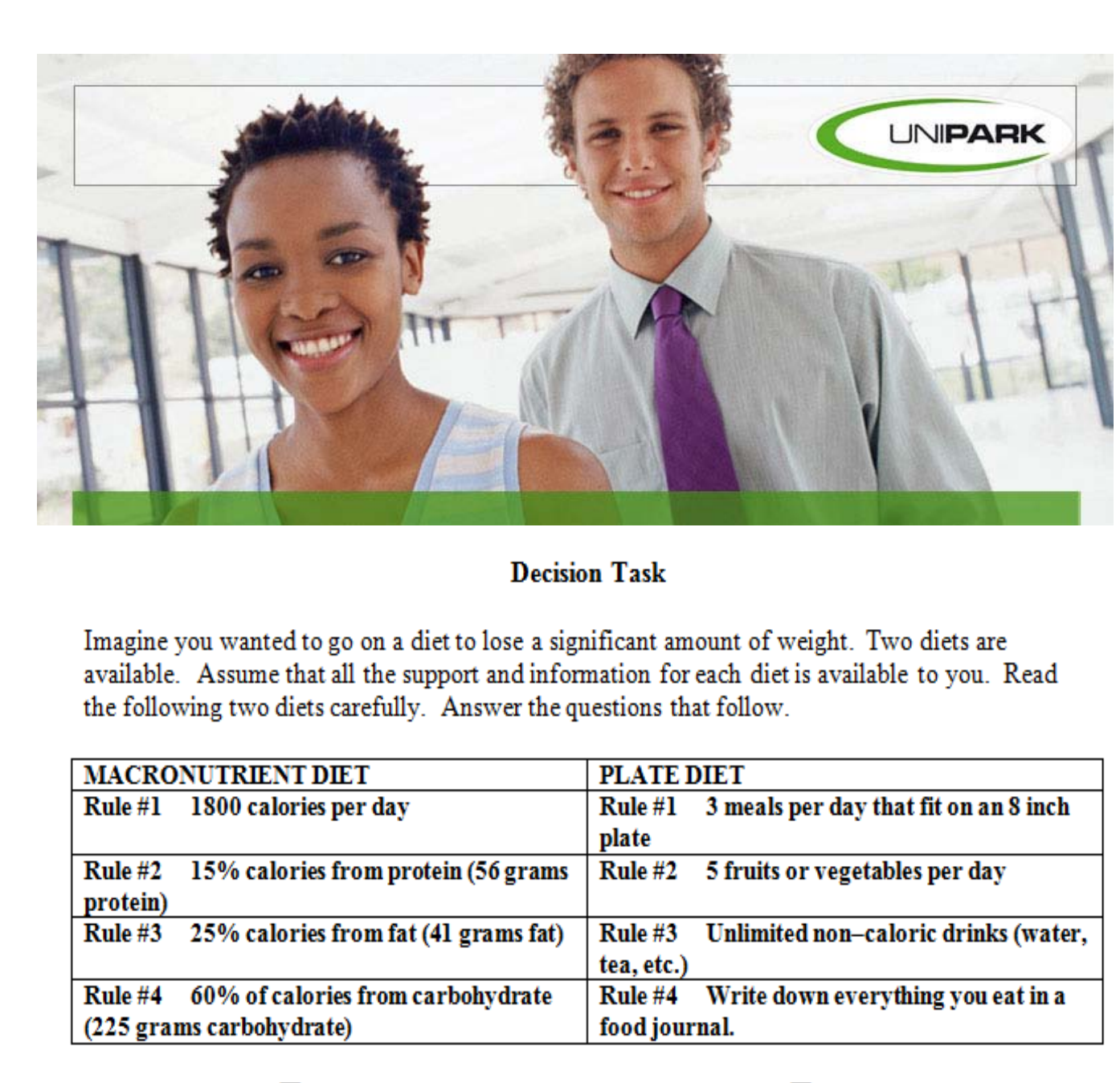

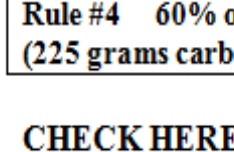
СHECK HRRE $\square$

Online Survey Stimuli

Weight Loss on Each Diet

7.00

6.50

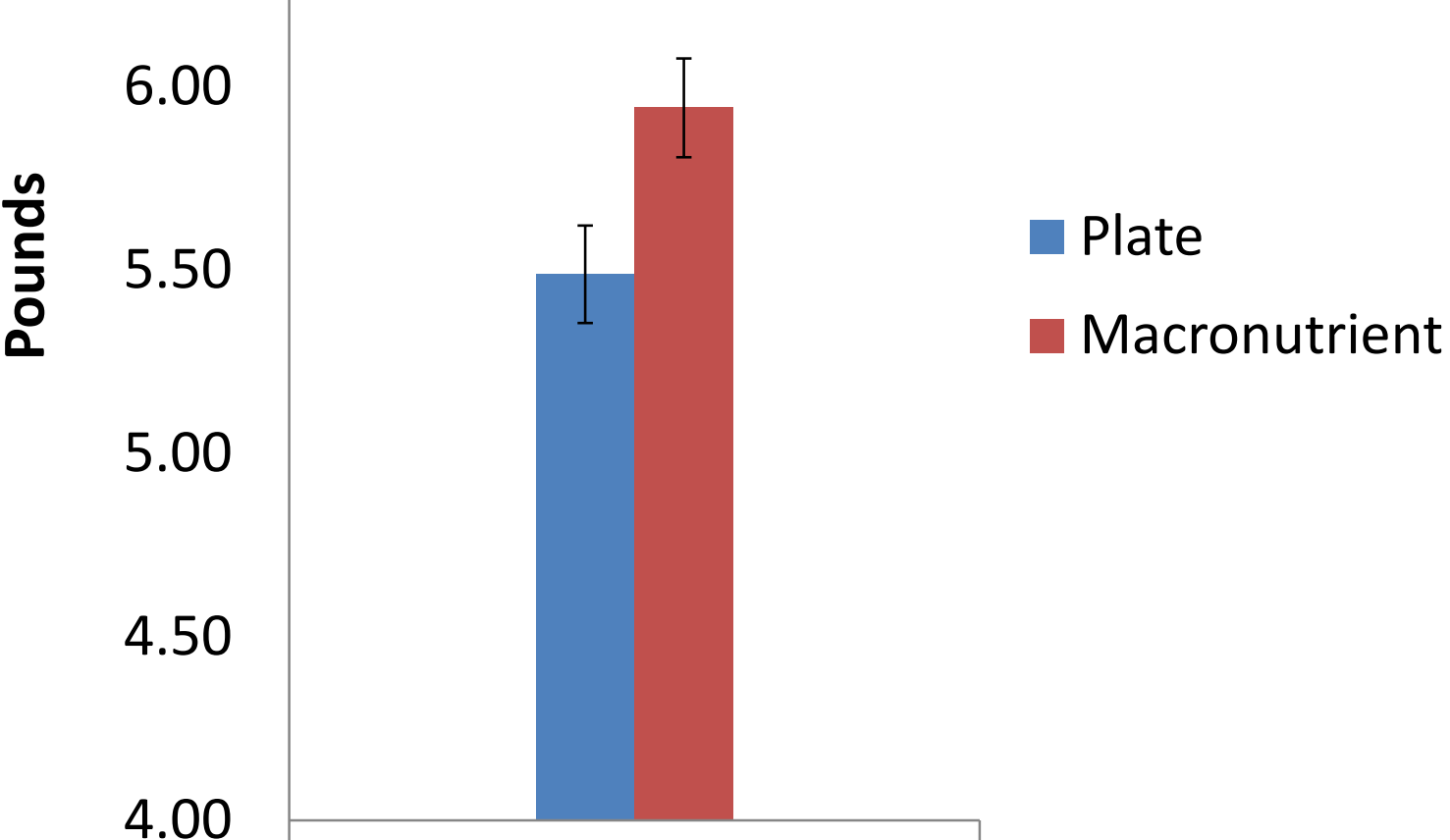

Cohen's $d=$

Importance of adhere do nor weight loss. diet efficacy, suggesting a potentially serious

\section{EXPERIMENT 2: EXERCISE}

Presented two exercise programs

Programs were equated on

- Number of rules

- Number of words

- Exercise efficacy*

${ }^{*}$ Data suggest that the simpler program may be more effective (Skinner 2005).

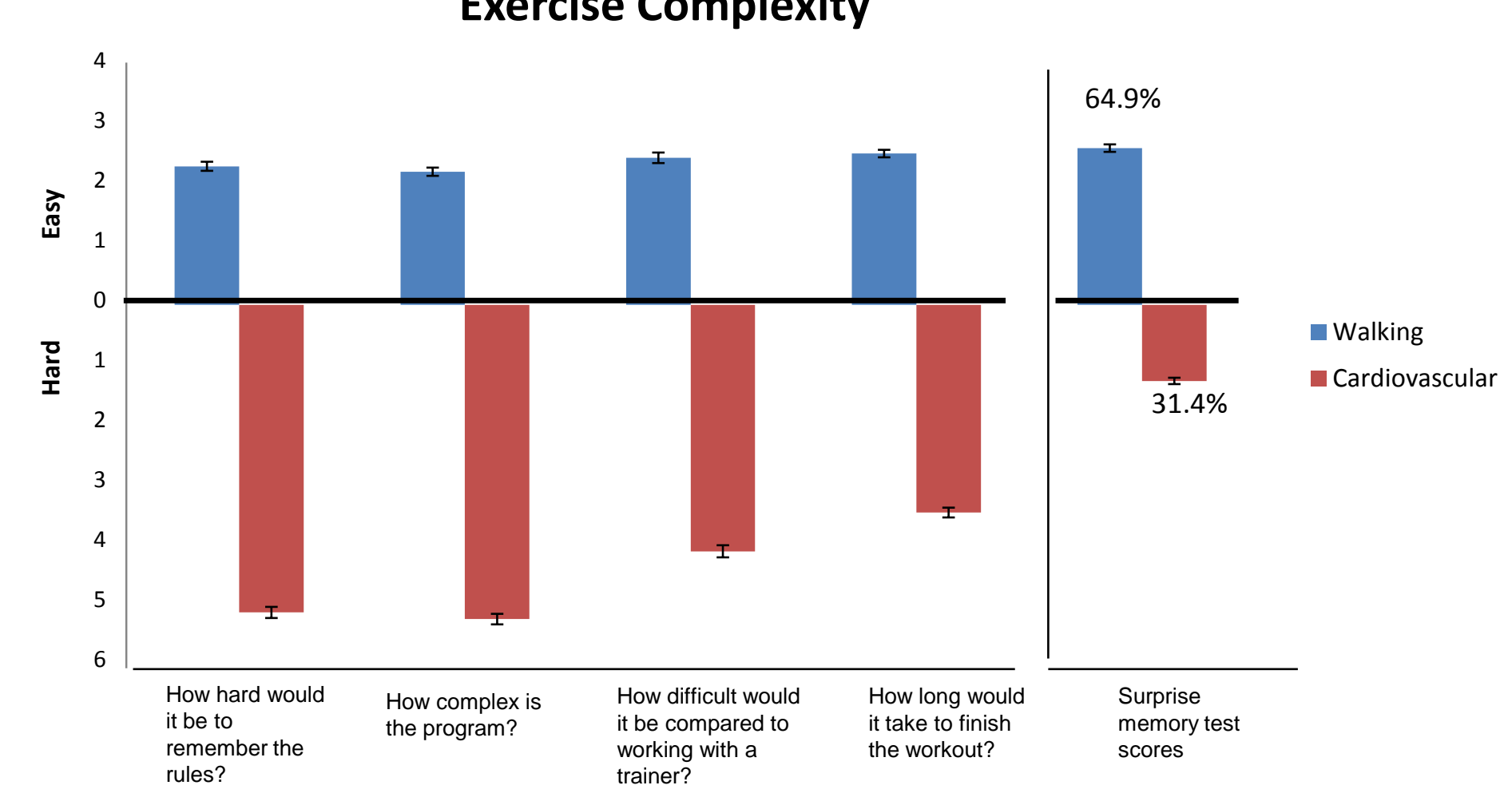

1) People accurately judged the Cardiovascular program as

more complex and harder to remember.

Accurate recall and recognition of exercise rules was

Exercise Adherence

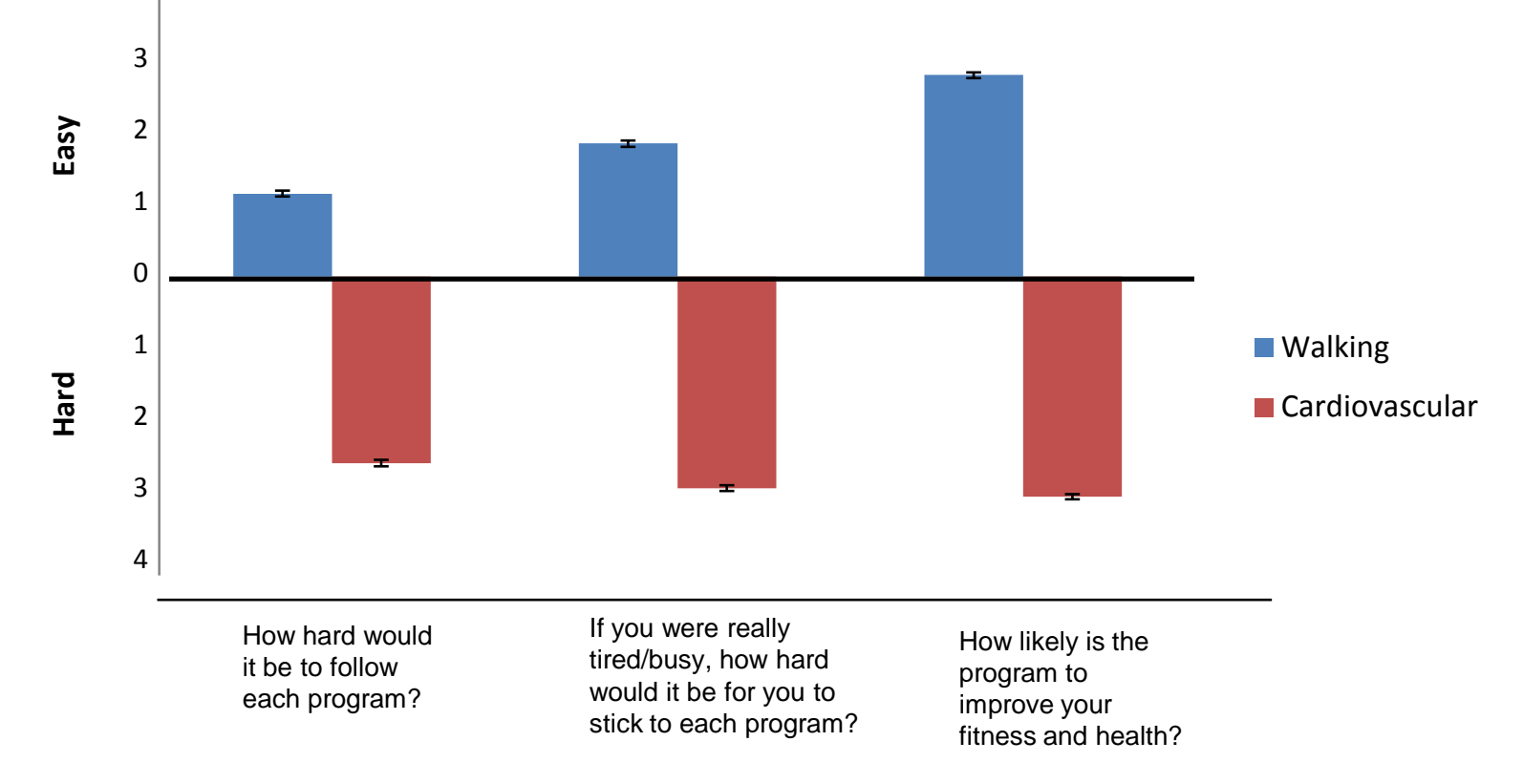

(3) People understand that simple programs

are much easier to adhere to

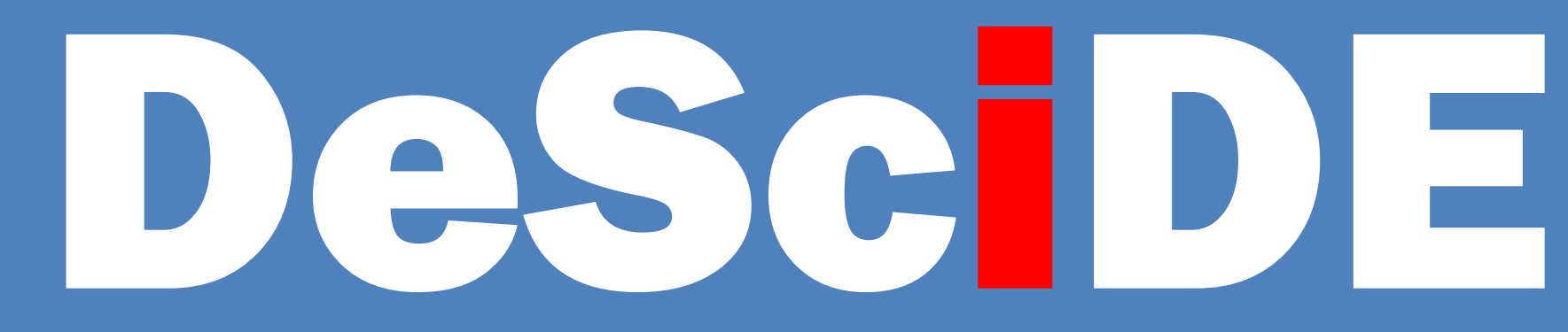

Engineering Laboratory

\section{CONCLUSIONS}

- Documents a "complex is better" bias when evaluating common diet and exercise (and perhaps other) health interventions.

- Documents large mnemonic benefits of simpler programs

- Indicates that the public tends to understand that simpler programs are easier to remember, follow, and adhere to.

- However, suggests a widespread lack of public understanding of the importance of adherence for weight-loss success.

\section{FUTURE DIRECTIONS.}

Ongoing studies are evaluating 'complex is better' type biases in:

- Professional health care workers (nutritionists; physicians; nurses; trainers; nursing-home workers);

- Cross-cultural studies

- Various age groups (e.g., Children; Adults; Older Adults)

- Other health Interventions (e.g., Pharmacological; Surgical)

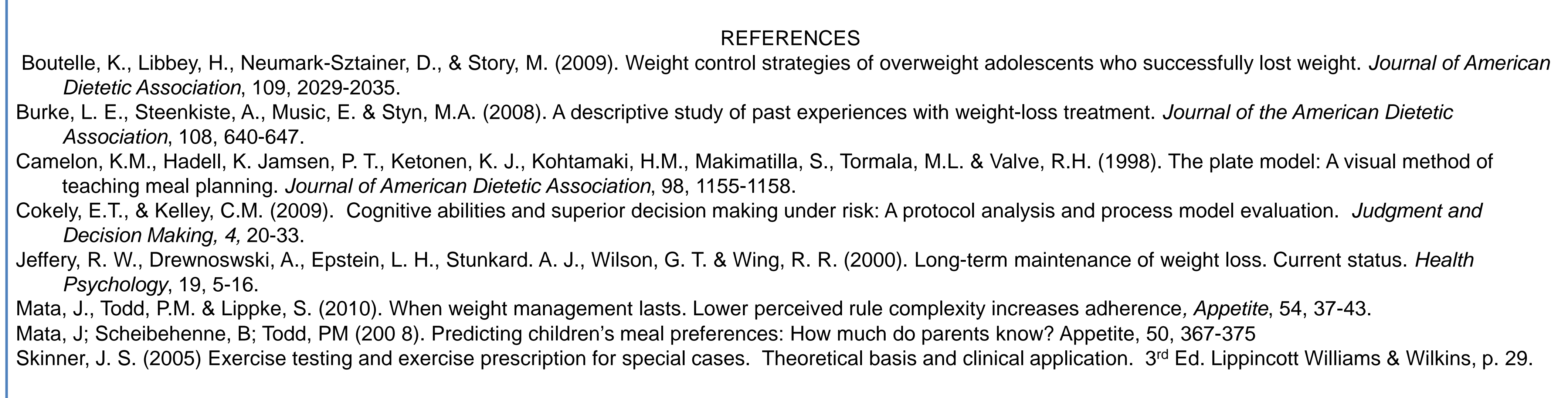

